University of Nebraska - Lincoln

DigitalCommons@University of Nebraska - Lincoln

Educational Psychology Papers and

Publications

Educational Psychology, Department of

2009

Parent Involvement as a Predictor of Teacher-Child Relationship Quality in Third Grade

Amanda J. Wyrick

amanda.wyrick@louisville.edu

Kathleen Moritz Rudasill

University of Nebraska-Lincoln, kmrudasill@vcu.edu

Follow this and additional works at: https://digitalcommons.unl.edu/edpsychpapers

Part of the Educational Psychology Commons

Wyrick, Amanda J. and Rudasill, Kathleen Moritz, "Parent Involvement as a Predictor of Teacher-Child Relationship Quality in Third Grade" (2009). Educational Psychology Papers and Publications. 127. https://digitalcommons.unl.edu/edpsychpapers/127

This Article is brought to you for free and open access by the Educational Psychology, Department of at DigitalCommons@University of Nebraska - Lincoln. It has been accepted for inclusion in Educational Psychology Papers and Publications by an authorized administrator of DigitalCommons@University of Nebraska - Lincoln. 
Published in Early Education \& Development 20:5 (2009), pp. 845-864;

doi: 10.1080/10409280802582803 Copyright () 2009 Taylor \& Francis Group, LLC.

Used by permission.

Published online September 30, 2009.

\title{
Parent Involvement as a Predictor of Teacher-Child Relationship Quality in Third Grade
}

\author{
Amanda J. Wyrick \& Kathleen Moritz Rudasill \\ University of Louisville \\ Corresponding author - Amanda Wyrick, College of Education and Human Development, \\ University of Louisville, Louisville, KY 40292; email amanda.wyrick@louisville.edu
}

\begin{abstract}
Research Findings: Research on teacher-child relationships is important, as the quality of this relationship is linked to numerous child outcomes in the areas of academic and social functioning. In addition, parent involvement has been identified as a significant factor in the successful development of a child. This study attempted to join these two lines of research by assessing the extent to which teacher-child relationship quality varies as a function of parent involvement. We used a sample of 894 third-grade children, mothers, and teachers from the National Institute of Child Health and Human Development (NICHD) Study of Early Child Care. Regression analyses were conducted to examine the relation between teacher-child relationships and parent involvement while controlling for known determinants of teacher-child relationship quality (i.e., gender and income). All variables were significantly related to teacher-child relationship quality. Parent involvement was negatively related to conflict. Furthermore, more parent involvement predicted less teacherchild conflict, but only for children from low-income families.

Practice or Policy: The results are discussed in terms of the importance of parent involvement to children's school adjustment, with specific importance for parents of low-income children.
\end{abstract}

A critical aspect of a child's healthy development is the formation of positive relationships with others. One relationship that can significantly enhance a child's school and social functioning is the teacher-child relationship (Baker, 2006; Hamre \& Pianta, 2005; Ladd, Birch, \& Buhs, 1999; Pianta \& Stuhlman, 2004). The quality of this relationship is influenced by both biologically based characteristics (Baker, 2006; Kesner, 2000; Rudasill, Rimm-Kaufman, Justice, \& 
Pence, 2006) and environmental characteristics (O'Connor \& McCartney, 2006; Pianta et al., 2005). One environmental characteristic that has been rarely examined in regard to the teacher-child relationship is level of parent involvement. Thus, the purpose of this study was to examine the extent to which parent involvement contributes to the quality of the teacher-child relationship. For the purposes of this study, parent involvement refers to a combination of a parent's actions, such as attendance at school meetings, and interactions with teachers, school personnel, and other parents (Barton, Drake, Perez, St. Louis, \& George, 2004).

The importance of teacher-child relationships and the contributions of parent involvement to the quality of these relationships can be better understood when placed in the larger context of a bioecological model of development (Bronfenbrenner\& Morris, 1998). This model emphasizes a set of nested structures with the child at the center. The microsystem comprises the activities, social roles, and interpersonal relationships directly experienced by the developing child and encompasses the child's relationships both at home and at school. Together, characteristics of the child (e.g., gender and socioeconomic status) and the environment (e.g., quality of parent relationship) influence development, and the quality of interactions between the child and the environment (e.g., teacher) can either buffer or exacerbate the child's risks for maladjustment. The child is also affected indirectly by elements of the mesosystem, which comprises the interactions between two or more settings of the microsystem. Just as a child's relationships at home and at school are important to development, the interactions between home and school contribute to healthy development (Bronfenbrenner \& Morris, 1998). Thus, the bioecological model illustrates the importance of considering interactions within and between systems when understanding positive outcomes for children. The current study is an examination of relationships between two microsystems. That is, we investigate the quality of the relationship between a child's home and school microsystems. Specifically, we investigate how one aspect of the home microsystem (parent involvement) contributes to one aspect of the school microsystem (the teacher-child relationship).

The quality of the teacher-child relationship has been identified as critical to academic and social outcomes of children (Hamre \& Pianta, 2005; Hughes, Cavell, \& Willson, 2001; Murray \& Greenberg, 2000; Pianta, Nimetz, \& Bennett, 1997). For example, Pianta et al. (1997) found that more positive teacherchild relationships are associated with children's higher scores on a test of ageappropriate concepts and language and higher teacher ratings of competence and work habits among 4-year-olds. Murray and Greenberg found that highquality teacher-child relationships (i.e., those in which children perceived their teachers as being emotionally supportive and responsive) promote children's positive social and emotional adjustment during elementary school. Emotional support, such as being aware of and responsive to student needs and creating 
a positive classroom climate, also contributes to increased academic achievement and less conflict with teachers in later grades (Hamre \& Pianta, 2005). In addition, high-quality teacher- child relationships further promote children's positive social adjustment in third and fourth grades, because peers tend to show greater social preference for children who receive more support from the teacher (Hughes et al., 2001).

Teacher-child relationship quality is often evaluated in terms of conflict and closeness. Conflict generally refers to the degree to which a teacher feels the relationship with the child is characterized by hostile and intense interactions. Closeness refers to the extent to which the relationship is felt to be warm, to be affectionate, and to contain open communication (Pianta, 1999; Pianta, Steinberg, \& Rollins, 1995). Each of these characteristics contributes uniquely to a child's academic and social development. Among children in elementary grades, relationships that are high in conflict contribute to school avoidance and less cooperative participation (Birch \& Ladd, 1997), fewer positive work habits (e.g., listening, participation, and compliance) and more disciplinary infractions (Hamre \& Pianta, 2001), lower academic performance (DiLalla, Marcus, \& Wright-Phillips, 2004; Pianta \& Stuhlman, 2004), increased externalizing and internalizing behavior problems, and lower social competence (Pianta \& Stuhlman, 2004). A high level of conflict has been linked more strongly than the level of teacher- child closeness to school outcomes for children in elementary school (Baker, 2006; Ladd et al., 1999). For example, Baker found that compared to close relationships, conflictual teacher-child relationships account for more variance in academic achievement and positive work behaviors (e.g., adjustment to the norms, routines, and expectations of the classroom) for children in elementary school.

Even so, teacher-child closeness has been linked to several positive outcomes for kindergarten children, such as increased visual and language scores and greater self-directedness (i.e., the extent of a child's independent or self-directed behavior in the classroom; Birch \& Ladd, 1997). The level of closeness is also related to higher academic ratings and social competence for children in preschool through first grade (Pianta \& Stuhlman, 2004). Children in kindergarten who develop a close relationship with teachers are more likely to have independent and cooperative styles of classroom participation, such as complying with classroom rules and displaying independent behaviors in the classroom, which can lead to higher levels of achievement (Ladd et al., 1999). The level of closeness in relationships with teachers may also impact children differently depending on ethnicity and behavioral characteristics. Burchinal, Peisner-Feinberg, Pianta, and Howes (2002) found that, for preschool minority children only, a close relationship with the teacher predicts better reading skills. In another study related to behavioral characteristics, a close relationship with a teacher served as a protective factor by increasing academic and social performance for elementary school children with behavior problems (Baker, 2006). Taken together, this research indicates that children with positive, supportive, 
and nonconflictual relationships with teachers are more likely to experience greater academic and social success.

Within the context of the bioecological theory of development, the teacherchild relationship can be conceptualized as developing from interactions between the child and the teacher. The nature of these interactions is affected by characteristics of the teacher and the child. Teachers bring various practices, perceptions, and beliefs to the classroom that can influence interactions with students. Indeed, teacher characteristics account for more variance than preschool children's temperament characteristics in teacher-child conflict and dependency (Rudasill et al., 2006). Kindergarten and first-grade teachers who expressed negative affect toward students in narratives about their students are more likely to have negative encounters in the classroom (Stuhlman \& Pianta, 2001). In addition, among preschool and kindergarten teachers, lower levels of stress, the selection of flexible and developmentally appropriate instructional activities, and higher levels of training (i.e., 4-year degree and teacher certificate) have all been found to contribute to higher levels of quality in teacherchild relationships (Mantzicopoulos, 2005; Pianta et al., 2005).

Child characteristics also contribute to the quality of the teacher-child relationship. For example, results from many studies have pointed to the importance of child gender in predicting teacher-child relationship quality (Hughes et al., 2001; Hughes, Gleason, \& Zhang, 2005; Murray \& Murray, 2004; O'Connor \& McCartney, 2006; Stuhlman \& Pianta, 2001). Specifically, research has demonstrated that teachers have more conflictual relationships with boys and closer relationships with girls (Baker, 2006; DiLalla et al., 2004; Hamre \& Pianta, 2001; Kesner, 2000; Ladd et al., 1999; Murray \& Murray, 2004). Teacher-child relationship quality is also related to the ethnicity of the child. Research shows that teachers perceive nonminority children as less dependent. As such, nonminority children tend to be more supported and to form closer and less conflictual ties with teachers (Hughes et al., 2005; Kesner, 2000; Ladd et al., 1999; Murray \& Murray, 2004). Furthermore, temperament (Rudasill et al., 2006), behavioral styles and/or behavioral problems (Ladd et al., 1999; Mantzicopoulus, 2005; Murray \& Murray, 2004; O'Connor \& McCartney, 2006; Stuhlman \& Pianta, 2001), and achievement (Mantzicopoulos, 2005) have all been linked to teacherchild relationship quality.

Children also bring to the classroom nonbiological characteristics (e.g., socioeconomic status) that influence both their relationships with teachers and the quality of their classroom experiences (O'Connor \& McCartney, 2006; Pianta et al., 2005). For example, the quality of interactions between teachers and children is lower when the majority of the preschool children in the classroom live below the poverty line (Pianta et al., 2005). Similarly, O'Connor and McCartney found that preschool through first-grade classrooms containing children with higher mean maternal education levels (a common proxy for socioeconomic status) have higher quality teacher-child relationships. 
One environmental child characteristic that has been connected to various school outcomes of children, but that has received almost no attention in the area of teacher-child relationships, is the level of parent involvement in a child's school experience (Cooper \& Crosnoe, 2007; Gonzalez-DeHass, Willems, \& Holbein, 2005; Hoover-Dempsey \& Sandler, 1995; Hughes \& Kwok, 2007; Simpkins, Weiss, McCartney, Kreider, \& Dearing, 2006). A parent's level of involvement is multi-determined. Hoover-Dempsey et al. (2005) suggested that parents become involved based on a parental role construction (e.g., parents' beliefs about what they are supposed to do in relation to the child's education); a sense of efficacy for helping; a perception of the extent to which they feel invited to become involved from either the school or their child; and various elements of the parents' life contexts, such as socioeconomic status, knowledge, time availability, and energy. Luster, Lekskul, and Oh (2004) found that low-income adolescent mothers are less involved in their firstgrade children's education when the quality of the home environment is lower (e.g., fewer learning materials in the home, less positive parental modeling, less acceptance and responsivity from the parent, and a limited variety of experiences for the child). Level of parent involvement has also been linked to factors related to the school. For example, schools with strong parent networks (i.e., parents report that they know and communicate frequently with other parents in their child's classroom) have higher levels of parent involvement (Sheldon, 2002).

Parents can become involved in the education of their children through participating at home and/or school. Home involvement refers to parent-child interactions on school-related or other learning activities (e.g., homework) that demonstrate a direct parental investment in education (Sheldon, 2002). School involvement refers to the extent to which parents interact with teachers and other school personnel through communication or involvement in school activities (e.g., chaperoning, volunteering, calling the teacher; Sheldon, 2002). Parent involvement at school was examined for the purposes of this study.

One component of parent involvement identified by Epstein (1995) is communication. Parent involvement targeted at communication with the school and teachers fosters social connections and higher quality relationships between the home and school environments (Miretzky, 2004). High-quality interactions between home and school may influence a parent's level of engagement with the school (i.e., attending school events, positive endorsement of school, and open communication with school personnel; Kohl, Lengua, \& McMahon, 2000).

Although the connection between forms of parent involvement, such as engagement with the teacher and school, and the teacher-child relationship has minimal support in the literature, parent involvement has been positively tied to the broader area of children's outcomes. In an extensive literature review, Gonzalez-DeHass et al. (2005) found support for a variety of positive school 
outcomes related to the level of parent involvement. These are children's increased school engagement, more intrinsic motivation for school success, a higher mastery goal orientation, increased motivation to read, and increased sense of locus of control for school outcomes

More specifically, both parents and teachers recognize the impact of highquality relationships between parents and teachers; such relationships work to benefit children because they facilitate a better understanding of children's needs, and, in turn, children perceive adults as unified about the importance of education (Miretzky, 2004). Hughes and Kwok (2007) suggested that social relatedness is critical to a first grader's school achievement. They found that when parents and children experience supportive relationships with the teacher, children have both direct gains in achievement and gains mediated by classroom engagement.

While the level of engagement between parent and teacher works to improve child outcomes it can also work to increase other levels of parent involvement. Knopf and Swick (2007) described the parent-teacher relationship as one of the most important precursors for parent involvement in the school and home. Furthermore, when teachers offer communication about a child's progress and ideas for helping the child, parent involvement rates increase significantly (Watkins, 1997). This literature builds a strong case for programs aimed at increased communication and quality relationships between parents and teachers, as well as increased parent involvement.

Collectively, the extant literature demonstrates that both teacher-child relationships and parent involvement are factors that are influential in schoolrelated outcomes for children. Although a variety of factors contribute to the quality of the teacher-child relationship and the level of parent involvement, our search of the literature revealed only one study that directly examined the relation between parent involvement and the teacher-child relationship. Specifically, Mantzicopoulos (2005) investigated the extent to which teacher reports of parent involvement in school activities were related to child reports of teacher-child relationship quality. He found that preschool children were more likely to report higher levels of conflict with their teacher when the teacher reported less positive parent relationships within the school. Our study builds upon this research by adding parent report of involvement and teacher report of teacher-child relationship quality. In addition, we address both gender and income in relation to parent involvement and quality of the relationship.

Given support from the literature, it is expected that girls will have higher levels of closeness with teachers and boys will have higher levels of conflict (Baker, 2006; DiLalla et al., 2004; Hamre \& Pianta, 2001; Kesner, 2000; Ladd et al., 1999; Murray \& Murray, 2004). It is also expected that income levels will make a difference in teacher relationship quality, with lower income children experiencing less closeness and more conflict $\left(\mathrm{O}^{\prime}\right.$ Connor \& McCartney, 
2006; Pianta et al., 2005). The literature also supports the possibility that parent involvement will significantly reduce negative outcomes (i.e., conflict with teachers) and increase positive outcomes (i.e., closeness with teachers). The purpose of this study was to fill the gap in this line of research, which led to two questions. First, to what extent is parent involvement related to teacher-child relationship quality? Second, in what way does parent involvement moderate the relationship between gender and income (previously established predictors of teacher-child relationship quality) and teacher- child relationship quality?

\section{Method}

\section{Participants}

Participants were children, their parents, and their third-grade teachers from the National Institute of Child Health and Human Development Study of Early Child Care (NICHD SECC). In 1991, mothers and children were recruited for participation in this study from hospitals near the following cities: Little Rock, AR; Irvine, CA; Lawrence, KS; Boston, MA; Philadelphia, PA; Pittsburgh, PA; Charlottesville, VA; Morganton, NC; Seattle, WA; and Madison, WI. Out of the 5,416 eligible participants, NICHD SECC investigators randomly selected 1,364 mothers and children to make up the final sample. The selected participants matched the demographic diversity (economic, educational, and ethnic) of the areas from which they were recruited. The present study used data from Phase 3 of the NICHD SECC, which was conducted when the study children were in the second through sixth grades. The sample for this study included third-grade children, their teachers, and their mothers. Owing to attrition from birth to third grade, the NICHD SECC included 1,007 study children at the start of the third phase of the study (when the children were in first grade). In addition, for the present study, children without complete data on the variables of interest were deleted listwise. Thus, the final sample comprised 894 children. Child participants were 427 boys and 467 girls; $80 \%$ were Caucasian, 14\% were Black/African American, and 6\% represented other ethnic groups. Teachers of child participants were primarily Caucasian (91\%) and female (93\%), with a mean of 14 years of teaching experience $(S D=10.4)$. Most mothers of participants had at least some college education $(n=287)$. For a full distribution of maternal level of education, see Table 1.

\section{Procedures}

Data for use in this study were collected during the children's fourth year of school (i.e., third grade). Third grade was chosen for a variety of reasons. It is widely acknowledged within the education community that third grade is 
Table 1. Mothers' Responses to the Question "What Level of School Have You Completed?"

\begin{tabular}{lrr}
\hline Response & $n$ & $\%$ \\
\hline Some high school & 23 & 2.6 \\
High school graduate or GED & 131 & 14.7 \\
Some college but no degree, AA, or vocational school beyond high school & 287 & 32.1 \\
Bachelor's from a college or university & 182 & 20.4 \\
Some graduate work or a master's & 94 & 10.5 \\
Law degree & 7 & 0.8 \\
More than one master's or a doctoral degree (MD, PhD, EdD, etc.) & 30 & 3.4 \\
\hline
\end{tabular}

$N=754$. GED = general equivalency diploma; $\mathrm{AA}=$ associate's degree.

a critical academic year for children, as it marks a shift from learning to read to reading to learn; indeed, most states' No Child Left Behind high-stakes testing begins in third grade (http://school.familyeducation.com/elementary-school/ assessment/56219.html). In addition, third grade marks the first time both parent reports of involvement and teacher reports of teacher-child relationship quality were collected in the NICHD SECC. Data from teachers were collected via questionnaires in the spring of the third-grade year, and data from mothers were collected in a laboratory setting. Children in the study were distributed across 32 states with 295 school divisions. Children were located within 747 schools in 827 classrooms. Further information regarding selection, sample, measures, data collection, and procedures can be found in the Manuals of Operation of the National Institute of Child and Human Development Early Child Care Research Network (1993).

\section{Measures}

Student-Teacher Relationship Scale. The quality of the teacherchild relationship within the school microsystem was captured by a single measure in the NICHD SECC database. The 15-item version of the Student-Teacher Relationship Scale: Short Form (Pianta, 2001) was completed by third-grade teachers. The STRS is a teacher-report instrument measures teachers' perceptions of conflict and closeness in their relationships with children. Items such as "This child and I always seem to be struggling with each other" and "This child easily becomes angry at me" comprise the 8-item conflict subscale of the STRS: Short Form. Items such as "I share an affectionate, warm relationship with this child" and "This child openly shares his/her feelings and experiences with me" comprise the 7-item closeness subscale. Teachers responded to items using a 
5-point Likert scale where 1 = definitely does not apply and $5=$ definitely applies. Cronbach's alphas with the current sample were as follows: closeness $(\alpha=.87)$ and conflict $(\alpha=.87)$.

Parent-Teacher Involvement Questionnaire. The NICHD SECC used two measures to assess the connection between the home and school microsystems. Parent and teacher reports of parent involvement were collected. We used only parent reports to maintain independence between reports of the teacher-student relationship and parent involvement. Mothers of third graders reported on their involvement using the 12-item Parent-Teacher Involvement Questionnaire. This questionnaire measures the extent to which parents have contact with their children's teachers, as well as the amount of involvement parents have in the schooling of their children. Sample items are "You feel welcome to visit your child's school" and "You send things to class like story books and other things." Parents responded on a 5 -point Likert scale $(0=$ not at all to $4=$ a great deal). For the purpose of this study, a composite score from Items 1 through 8 on the questionnaire was derived to exclude items not directly related to the construct of parent involvement (e.g., "Your school is a good place for your child to be"). Cronbach's alpha for the current sample was .88.

Income. Income was reported by mothers of third graders using the Family Employment and Income form. This form asked parents "Finally, how much total income, before taxes, did your family receive in 1999?" This question allowed for the calculation of annual total family income.

\section{Results}

\section{Descriptive Analyses}

We conducted descriptive analyses of scores on teacher-child relationship quality and parent involvement. Teacher-child relationship quality was high in this sample, with children's relationships with teachers generally low in conflict and high in closeness. Parent involvement in the sample was high, with parents reporting, on average, that they encouraged education and were involved with the school "a lot." The average family income for this group was $\$ 77,218$ (SD = $\$ 67,376)$. All means and standard deviations are displayed in Table 2.

Correlational analyses revealed that all scores had relatively low intercorrelations (i.e., less than .3), with the exception of teacher-reported conflict and closeness. These variables were moderately related $(r=-.375)$, indicating that as teacher-child conflict increased, teacher-child closeness decreased. Further examination of the correlation matrix revealed several small but significant relationships among the predictor variables and the outcome variables. 
Table 2. Correlation Coefficients for Relations Between Child Characteristics and Teacher-Child Relationships

\begin{tabular}{|c|c|c|c|c|c|c|c|c|}
\hline Variable & M & SD & Range $\mathrm{G}$ & Gender & Income & $\begin{array}{l}\text { Family } \\
\text { Involvement }\end{array}$ & $\begin{array}{l}\text { Parent } \\
\text { Conflict }\end{array}$ & Closeness \\
\hline \multicolumn{9}{|l|}{ Child attributes } \\
\hline Gender & & & & - & .001 & .01 & $-.186^{* *}$ & $.215^{* *}$ \\
\hline $\begin{array}{l}\text { Family } \\
\text { income }\end{array}$ & $77,218.40$ & $67,376.95$ & $2,500-500,001$ & $1 \quad .001$ & - & $.096^{* *}$ & $-.163^{* *}$ & $.084^{*}$ \\
\hline $\begin{array}{l}\text { Parent } \\
\text { involvemen }\end{array}$ & 23.86 & 5.64 & 3-32 & .01 & $.096^{* *}$ & - & $-.117^{* *}$ & $.133^{* *}$ \\
\hline \multicolumn{9}{|c|}{ Teacher-child relationships } \\
\hline Conflict & 11.45 & 5.93 & $7-34$ & $-.186^{* *}$ & $-.163^{* *}$ & $-.117^{* *}$ & - & $-.375^{* *}$ \\
\hline Closeness & 33.19 & 5.01 & $16-40$ & $.215^{* *}$ & $.084^{*}$ & $.133^{* *}$ & $-.375^{\star *}$ & - \\
\hline
\end{tabular}

${ }^{*} p<.05 ;{ }^{* *} p<.01$

Children rated higher in conflict were males, children with lower family incomes, and children with lower levels of parent involvement. Children rated higher in closeness were females, children with higher family incomes, and children with higher levels of parent involvement. Table 2 shows the correlation matrix.

\section{Parent Involvement and Teacher-Child Relationship Quality}

To determine the extent to which parent involvement predicts teacherchild relationship quality in the third grade beyond the effects of gender and income, a series of hierarchical regression analyses were conducted with teacher-child conflict and closeness as the dependent variables. Children's gender and family income were entered in the first step, and parent involvement was entered in the second step. To determine the moderating effect of parent involvement on teacher-child relationship quality, the third step comprised all two-way interactions between parent involvement, gender, and income. Only those interactions that were significant are presented here. Results are shown in Tables 3 (closeness) and 4 (conflict).

Closeness. For Step 1, child gender and family income significantly predicted teacher-child closeness $\left(F_{2,869}=26.56, p<.001, R^{2}=.06\right)$. Girls and children with higher family incomes were more likely to experience closeness with their teachers. Together, these child variables explained $6 \%$ of the variance in teacher-child closeness. With the addition of parent involvement in Step 2 , the model remained significant $\left(F_{3,869}=22.79, p<.001, R^{2}=.07\right)$. Re- 
Table 3. Hierarchical Regression Analysis Predicting Teacher-Child Closeness From Gender, Income, and Parent Involvement

\begin{tabular}{lccccc}
\hline Variable & $B$ & SEB & $\beta$ & $R^{2}$ & $\Delta R^{2}$ \\
\hline Step 1 & & & & .058 & $.058^{* * *}$ \\
$\quad$ Gender & 2.24 & .33 & $.23^{* * *}$ & & \\
$\quad$ Income & .00000622 & .00 & $.084^{*}$ & & \\
Step 2 & & & & .073 & $.015^{* * *}$ \\
$\quad$ Gender & 2.23 & .33 & $.22^{* * *}$ & & \\
Income & .00000533 & .00 & $.072^{*}$ & & \\
Parent involvement & .110 & .03 & $.125^{* * *}$ & & \\
\hline
\end{tabular}

${ }^{*} p<.05 ;{ }^{* * *} p<.001$

Table 4. Hierarchical Regression Analysis Predicting Teacher-Child Conflict From Gender, Income, and Parent Involvement

\begin{tabular}{llllll}
\hline Variable & \multicolumn{1}{c}{$B$} & SEB & $\beta$ & $R^{2}$ & $\Delta R^{2}$ \\
\hline Step 1 & & & & .064 & $.064^{* * *}$ \\
$\quad$ Gender & -2.27 & .388 & $-.192^{* * *}$ & & \\
$\quad$ Income & -.0000143 & .000 & $-.163^{* * *}$ & & .073 \\
Step 2 & & & & $.01^{* * *}$ \\
$\quad$ Gender & -2.26 & $.39-.191^{* * *}$ & & \\
Income & -.0000136 & .000 & $-.154^{* * *}$ & & \\
$\quad$ Parent involvement & -.10 & .03 & $-.095^{* * *}$ & & $.005^{*}$ \\
Step 3 & -2.24 & .385 & $-.190^{* * *}$ & & \\
$\quad$ Gender & -.0000461 & .000 & $-.526^{* * *}$ & & \\
Income & -.196 & .052 & $-.187^{* * *}$ & & \\
$\quad$ Parent involvement & .00000130 & .000 & $.40^{*}$ & \\
Income $\times$ Parent Involvement & &
\end{tabular}

${ }^{*} p<.05 ; * * *<.001$

sults indicated that parent involvement was a significant predictor of teacherchild closeness beyond gender and income $(\beta=.12, p<.001)$. Parent involvement explained an additional 1\% of the variance in closeness. In Step 3 of the model, the interaction between parent involvement and gender was not a significant predictor of teacher- child closeness beyond income, gender, and parent involvement $(\beta=-.16, p>.05)$. Similarly, the interaction between parent involvement and income was not a significant predictor of teacher-child closeness beyond income, gender, and parent involvement $(\beta=-.15, p>.05)$.

Conflict. Children's gender and family income significantly predicted conflict $\left(F_{2,869}=29.42, p<.001, R^{2}=.06\right)$, with boys and children with lower family 
incomes more likely to be perceived by teachers as having a conflictual relationship. These child and family variables accounted for $6 \%$ of the total variance in teacher-child conflict. In Step 2, parent involvement was added to the model, and the model remained significant $\left(F_{3,869}=22.59, p<.001, R^{2}=.07\right)$. This indicated that parent involvement was a significant predictor of teacher-child conflict $(\beta=-.095, p<.001)$ and accounted for an additional $1 \%$ of the variance. In Step 3 of the model, the interaction of parent involvement and gender was not a significant predictor above and beyond gender, income, and parent involvement $(\beta=.230, p>$.05). However, the interaction of parent involvement and income significantly predicted teacher conflict above and beyond gender, income, and parent involvement $(\beta=.40, p=.014)$.

To understand the nature of the interaction between parent involvement and income in predicting teacher-child conflict and closeness, an additional set of analyses was conducted to examine the contribution of parent involvement to teacher-child conflict for children from different income levels (Pedhazur, 1997). The sample was first divided into three equal-size income groups (i.e., low, middle, and high income) based on total family annual income. The low-income group was made up of families with incomes less than $\$ 47,500$, the middle-income group was made up of families with incomes from $\$ 47,500$ to $\$ 75,000$, and the high-income group was those families with incomes more than $\$ 75,000$. For each income group, conflict was regressed on gender and parent involvement. We found that less parent involvement was significantly related to more teacher-child conflict, but only for those children in the low-income group $\left(F_{2,291}=8.455, p=.013, R^{2}=.048\right)$. Parent involvement accounted for an additional $2 \%$ of the variance in conflict for children in the lowest income group as compared to $0 \%$ in the middle and high groups. To obtain more information about the interaction between parent involvement and family income in predicting teacher-child conflict, regression lines were calculated for each income group (low, middle, and high). The resulting slopes showed the level of teacher-child conflict predicted by parent involvement for the average child in each income group. This visual representation of the interaction (see Figure 1) shows that children in the low-income group were more likely than their middle- and high-income peers to have higher teacher-child conflict if their parents reported less involvement with teachers.

\section{Discussion}

Three main findings emerged from this study. First, parent involvement was significantly related to teacher-child closeness; higher levels of parent involvement predicted more closeness in the teacher-child relationship. Second, parent involvement was significantly related to teacher-child conflict; lower levels of parent involvement predicted higher levels of conflict in the teacher-child relationship. Finally, parent involvement and family income worked together 


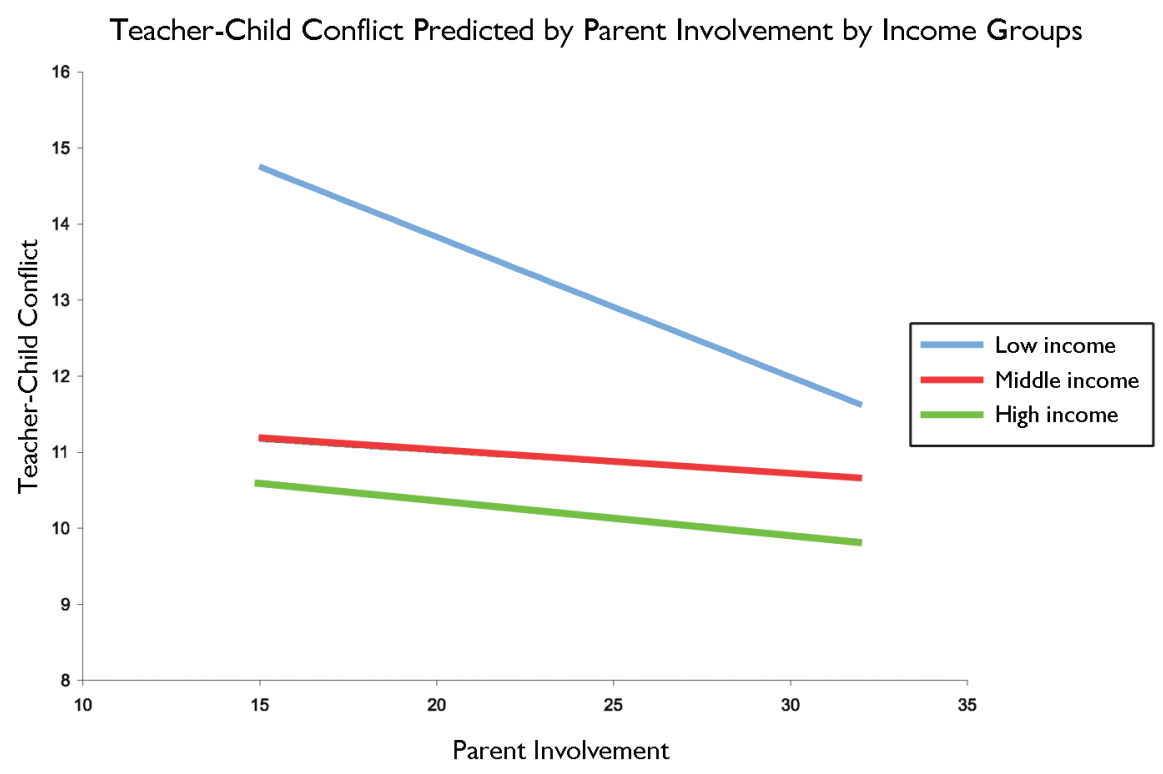

Figure 1. Teacher-child conflict predicted by parent involvement by income group.

to contribute to teacher-child conflict. Also, consistent with previous findings that document gender and income as predictors of teacher-child relationship quality, both variables contributed to teacher-child closeness and conflict. Girls were rated as experiencing more closeness, whereas boys were rated as experiencing more conflict. Children with lower family incomes were rated as experiencing higher levels of conflict and lower levels of closeness with their teachers. Considered within a bioecological framework, these findings emphasize the importance of connections between microsystems (i.e., home and school) for children's high-quality experiences in the school microsystem. This is particularly true for children from lower income homes, emphasizing the contribution of child characteristics to the operations in and between microsystems.

\section{Parent Involvement}

Children with more involved parents were more likely to have close relationships with their teachers. These children with high levels of parent involvement were also less likely to have relationships with teachers characterized by high levels of conflict. These results suggest that parents who are more involved in their child's schooling (i.e., feeling welcome at the school, communicating with the teacher) influence the relationship between the child and the teacher. However, the exact nature of the parent's influence cannot be deter- 
mined from these results. It is possible that a parent's involvement in a child's academic life influences the teacher-child relationship in two ways: through the child and through the teacher.

Parent involvement in children's schooling may influence children's attitudes toward school and their subsequent relationships with teachers. A parent's positive outlook on the school environment, including the teachers and administrators, may be imitated by the child. This hypothesis is congruent with previous research indicating that within a warm parent-child relationship, parental beliefs and behaviors about school and achievement are internalized by the child, leading to increased engagement in achievement-related behaviors (Simpkins et al., 2006). Furthermore, evidence shows that when parents are involved in a child's schooling the child reports more effort, more inherent interest in learning, and increased self-efficacy for academic tasks (e.g., reading; Gonzalez-DeHass et al., 2005). Hoover- Dempsey and Sandler (1995) postulated that parents' modeling of school-related behaviors conveys parental value of school, leading to a likely increase in children's sense of the importance of school. Taken together, research lends support to the hypothesis that parent involvement works to increase teacher-child relationship quality through modeling and instilling positive feelings about the school environment in the child. This in turn may promote positive teacher-child relationships.

A parent's involvement with the school may also promote positive teacherchild relationships by influencing teachers' perceptions of children. A parent who feels welcome in the child's school, initiates and maintains communication with the teacher, and feels positive about the school environment is more likely to have a high-quality relationship with the teacher than a parent who is relatively uninvolved. This parent-teacher relationship may form the basis for a positive teacher- child relationship. One review of the literature supports the notion that a child's increased academic achievement when parents are involved at school may occur because teachers grant more of their time and attention to children of involved parents (Finn, 1998). Thus, supportive parentteacher and teacher-child relationships can work together to increase early elementary school children's gains in achievement (Hughes \& Kwok, 2007). Parent involvement, characterized by a positive parent-teacher relationship, may work to improve teacher-child relationship quality by encouraging more attention and positive interactions from teacher to child.

\section{Parent Involvement and Income}

Our finding that parent involvement was related to lower teacher-child conflict only for the children in the lowest income group is congruent with related areas of research. Specifically, Cooper and Crosnoe (2007) found that parent involvement increased academic orientations for economically disadvantaged youth but decreased academic orientations for nondisadvantaged youth. On a related note, parent involvement in young children's literacy activities has been 
shown to diminish the achievement gap between children of highly and poorly educated mothers (Dearing, Kreider, Simpkins, \& Weiss, 2006). These results point to additional evidence supporting the value of parent involvement, particularly for promoting outcomes in children from low-income families.

The fact that more parent involvement predicted less teacher-child conflict for low-income students can perhaps be explained by understanding the decreased level of resources available to low-income youth. Pianta et al. (2005) concluded that the quality of interactions between teachers and children were lower for those below the poverty line because of the lack of available classroom and community resources for children in poverty. Indeed, children living in poverty experience higher levels of emotional and behavioral problems, lower academic functioning, and lower levels of physical health, often mediated by the lack of social support and the increased level of parent stress created by poverty (Seccomobe, 2000). Furthermore, emotional and behavioral distress of youth is exacerbated by the decreased positive parenting (i.e., effective discipline, responsiveness) related to stress from economic pressure (Gershoff, Aber, Raver, \& Lennon, 2007; Mistry, Vandewater, Huston, \& McLoyd, 2002; Yeung, Linver, \& Brooks-Gunn, 2002). Thus, relational resources, such as high teacher-child relationship quality, become very important for children living below the poverty line. Parent involvement may matter more for low-income youth because they have multiple risk factors (i.e., lack of resources and increased parental stress) for teacher conflict and poor academic outcomes.

The presence and involvement of a parent in the area of academics may help to alleviate some of these risk factors. Parent involvement and support for academics may work to create a higher quality home environment and supportive parent- child relationship, both of which have been shown to improve the success of a child in school. Luster et al. (2004) found that among low-income adolescent mothers, when the quality and support of the home environment improved, teachers rated children as more motivated. In the context of warm parent-child relationships children internalize their parents' academic values (Simpkins et al., 2006). Low-income children with parents who demonstrate higher levels of engagement with the school (i.e., feel the teacher is interested in getting to know them, ask questions of or make suggestions to the teacher) may feel more efficacious in terms of succeeding in all aspects of school, including having a positive, less conflictual relationship with the teacher (HooverDempsey \& Sandler, 1995).

\section{Limitations}

Several limitations require mention. This sample was relatively homogenous on two important variables: income and teacher-child relationship quality. With regard to income, children in this study tended to come from higher socioeconomic classes (the mean income was $\$ 77,218$ ). Given the results of the 
present study, it would be beneficial to include a sample with more socioeconomic diversity. This would allow for a better examination of the interaction between income and parent involvement as a predictor of teacher-child relationship quality. The sample was also relatively homogenous on ratings of teacher-child relationship quality. Overall, teachers and children included in this study had relationships characterized by low levels of conflict and high levels of closeness. It is important to note that, even with restricted ranges for income and teacher-child relationship quality, we still found associations between parent involvement, income, and teacher-child conflict. Thus, these findings point to the value of examining connections between these constructs with children from varying socioeconomic backgrounds. In addition, there is one measurement issue that acts as a limitation within the study. Our construct of parent involvement was based on parent report. This method of rating lends itself to the possibility of social desirability. Parents may have over-reported involvement with the school. Such a bias might have led to an underestimation of effect size for parent involvement. Finally, it is important to note that our analytical approach assumed directionality between constructs such that parent involvement contributes to teacher-child relationship quality. Indeed, it could be that teacher-child relationship quality contributes to parent involvement. Future work will need to investigate the direction of this relationship further.

\section{Future Research and Implications}

According to Bronfenbrenner and Morris (1998), a child develops in the center of a set of nested structures. Whereas the microsystem focuses on relationships and activities across different environments, the mesosystem focuses on the interplay of two or more settings within the microsystem. The bioecological model of development emphasizes not only the relationships a child has at home and school but the interplay between the two environments. From this theoretical perspective, the findings of the current study suggest areas of future research and implications for child development.

Because findings from the current study support child characteristics as contributors to teacher-child relationship quality, it is important to extend this examination of differences in quality based on other child characteristics, such as the diagnosis of an emotional/behavioral disorder. Previous research has documented a relationship between behavioral problems and teacher-child relationship quality, indicating that children with more aggression (Hughes et al., 2001), more internalizing and externalizing symptomatology (Murray \& Murray, 2004), and antisocial behaviors (i.e., aggression, arguing, and object possessiveness; Ladd et al., 1999) have lower quality teacher-child relationships. We propose to extend this research by investigating how parent involvement moderates the relationship between the presence of an emotional/behavioral disorder and teacher-child relationship quality. More specifically, does parent 
involvement matter differently for children with a diagnosis of an emotional/ behavioral disorder? Some studies have suggested that parent involvement may have a negative impact on student outcomes because of the sheer nature of engagement (Finn, 1998). Parent contact for children with emotional/behavioral disorders may be more negative and may occur during times of stress.

Finally, the relationship between income and teacher-child relationship quality warrants further investigation. Although one area of weakness in the study is homogeneity of income, this same area offers directions for future research. Given that even with a relatively privileged sample we still found a significant relationship between parent involvement and low income suggests a strong need for research investigating this interaction with a more socioeconomically diverse sample. Specifically, a sample with more low-income students would allow for further exploration of the interaction between parent involvement and teacher conflict. As research points out, income is a multifaceted construct influencing many variables in families' lives, such as family stress and resources (Gershoff et al., 2007; Mistry et al., 2002; Yeung et al., 2002). Further research needs to investigate the mechanisms by which parents of lower income groups become involved in the academic areas of their children's lives.

The results of the current study lend valuable information to the fields of policy and practice. Whereas previous research has strongly linked the quality of the teacher-child relationship to a child's success (Birch \& Ladd, 1997; Ladd et al., 1999; Pianta \& Stuhlman, 2004), this study points to significant predictors of this relationship. Gender, income, and parent involvement are all significant predictors of a quality relationship between teacher and child. This study influences practice in the area of teacher preparation. Given that boys, low income, and low parent involvement all predict decreased levels of closeness and increased levels of conflict, they represent areas of special consideration in teacher preparation courses. These findings illustrate the importance of staying aware of the multiple factors that influence child development and, more specifically, teacher-child relationship quality.

In addition to teacher preparation and practice, the results regarding parent involvement serve to inform school policy. Given that teacher-child relationships are predictors of success, and parent involvement predicts the quality of this relationship, schools should seek ways to increase parent involvement. This study's finding suggest that the influence of parents goes beyond their physical involvement (e.g., attending conferences, chaperoning) to the feeling of "engagement" within the school. Furthermore, schools should look for ways to involve low-income parents, as parent involvement matters more for this group than any other. Teachers and schools can work to create space within both the school and home for disadvantaged parents to contribute to the education of their children. School policymakers can look to identify barriers to engagement for low-income parents. It is critical that schools use this information 
not only to seek to increase actual parental presence in the schools but to create an environment in which parents feel welcomed and engaged. Once these barriers are overcome and the school is viewed as positive and welcoming by parents, involvement increases, thus serving as a protective factor for quality relationships with teachers.

\section{References}

Baker, J. A. (2006). Contributions of teacher-child relationships to positive school adjustment during elementary school. Journal of School Psychology, 44, 211-229.

Barton, A. C., Drake, C., Perez, J. G., St. Louis, K., \& George, M. (2004). Ecologies of parent engagement in urban education. Educational Researcher, 33(4), 3-12.

Birch, S. H., \& Ladd, G. W. (1997). The teacher-child relationship and children's early school adjustment. Journal of School Psychology, 35, 61-79.

Bronfenbrenner, U., \& Morris, P. A. (1998). The ecology of developmental processes. In R. M. Lerner (Ed.), Theoretical models of human development (5th ed., Vol. 1, pp. 993-1028). New York: Wiley.

Burchinal, M. R., Peisner-Feinberg, E., Pianta, R., \& Howes, C. (2002). Development of academic skills from preschool through second grade: Family and classroom predictors of developmental trajectories. Journal of School Psychology, 40, 415-436.

Cooper, C. E., \& Crosnoe, R. (2007). The engagement in schooling of economically disadvantaged parents and children. Youth E Society, 38, 372-291.

Dearing, E., Kreider, H., Simpkins, S., \& Weiss, H. B. (2006). Family involvement in school and low-income children's literacy: Longitudinal associations between and within families. Journal of Educational Psychology, 98, 653-664.

DiLalla, L. F., Marcus, J. L., \& Wright-Phillips, M. V. (2004). Longitudinal effects of preschool behavioral styles on early adolescent school performance. Journal of School Psychology, 42, 385-401.

Epstein, J. L. (1995). School/family/community partnerships: Caring for the children we share. Phi Delta Kappan, 76, 701-712.

Finn, J. D. (1998). Parental engagement that makes a difference. Educational Leadership, 55(8), 20-24.

Gershoff, E. T., Aber, J. L., Raver, C. C., \& Lennon, M. C. (2007). Income is not enough: Incorporating material hardship into models of income associations with parenting and child development. Child Development, 78, 70-95.

Gonzalez-DeHass, A. R., Willems, P. P., \& Holbein, M. F. D. (2005). Examining the relationship between parental involvement and student motivation. Educational Psychology Review, 17, 99-123.

Hamre, B. K., \& Pianta, R. C. (2001). Early teacher-child relationships and the trajectory of children's school outcomes through eighth grade. Child Development, 72, 625-638.

Hamre, B. K., \& Pianta, R. C. (2005). Can instructional and emotional support in the firstgrade classroom make a difference for children at risk of school failure? Child Development, 76, 949-967.

Hoover-Dempsey, K. V., Walker, J. M. T., Sandler, H. M., Whetsel, D., Green, C. L., Wilkins, A. S., et al. (2005). Why do parents become involved? Research findings and implications. The Elementary School Journal, 106, 105-130. 
Hughes, J. N., Cavell, T. A., \& Willson, V. (2001). Further support for the developmental significance of the quality of the teacher-student relationship. Journal of School Psychology, 39, 289-301.

Hughes, J. N., Gleason, K. A., \& Zhang, D. (2005). Relationship influences on teachers' perceptions of academic competence in academically at-risk minority and majority first grade students. Journal of School Psychology, 43, 303-320.

Hughes, J., \& Kwok, O. (2007). Influence of student-teacher and parent-teacher relationships on lower achieving readers' engagement and achievement in the primary grades. Journal of Educational Psychology, 99, 39-51.

Kesner, J. E. (2000). Teacher characteristics and the quality of child-teacher relationships. Journal of School Psychology, 28, 133-149.

Kohl, G. O., Lengua, L. J., \& McMahon, R. J. (2000). Parent involvement in school: Conceptualizing multiple dimensions and their relations with family and demographic risk factors. Journal of School Psychology, 6, 501-523.

Knopf, H. T., \& Swick, K. J. (2007). How parents feel about their child's teacher/school: Implications for early childhood professionals. Early Childhood Education Journal, 34, 291-296.

Ladd, G. W., Birch, S. H., \& Buhs, E. S. (1999). Children's social and scholastic lives in kindergarten: Related spheres of influence? Child Development, 79, 1373-1400.

Luster, T., Lekskul, K., \& Oh, S. M. (2004). Predictors of academic motivation in first grade among children born to low-income adolescent mothers. Early Childhood Research Quarterly, 19, 337-353.

Mantzicopoulos, P. (2005). Conflictual relationships between kindergarten children and their teachers: Associations with child and classroom context variables. Journal of School Psychology, 43, 425-442.

Miretzky, D. (2004). The communication requirements of democratic schools: Parentteacher perspectives on their relationship. Teachers College Record, 4, 814-851.

Mistry, R. S., Vandewater, E. A., Huston, A. C., \& McLoyd, V. C. (2002). Economic well-being and children's social adjustment: The role of family process in an ethnically diverse low-income sample. Child Development, 73, 935-951.

Murray, C., \& Greenberg, M. T. (2000). Children's relationship with teachers and bonds with school: An investigation of patterns and correlates in middle childhood. Journal of School Psychology, 38, 423-445.

Murray, C., \& Murray, K. M. (2004). Child level correlates of teacher-student relationships: An examination of demographic characteristics, academic orientations, and behavioral observations. Psychology in the Schools, 41, 751-762.

National Institute of Child Health and Human Development, Early Child Care Research Network (1993). The NICHD Study of early child care: A comprehensive longitudinal study of young children's lives. ERIC Document Reproduction Service, No. ED 3530870.

O'Connor, E., \& McCartney, K. (2006). Testing associations between young children's relationships with mothers and teachers. Journal of Educational Psychology, 98, 87-98.

Pedhazur, E. J. (1997). Multiple regression in behavioral research: Explanation and prediction. Belmont, CA: Thomson Learning.

Pianta, R. C. (1999). Enhancing relationships between children and teachers. Washington, DC: American Psychological Association.

Pianta, R. C. (2001). Student-teacher relationship scale. Odessa, FL: Psychological Assessment Resources, Inc. 
Pianta, R. C., Howes, C., Burchinal, M., Bryant, D., Clifford, R., Early, D., et al. (2005). Features of pre-kindergarten programs, classrooms, and teachers: Do they predict observed classroom quality and child-teacher interactions? Applied Developmental Science, 9, 144-159.

Pianta, R. C., Nimetz, S. L., \& Bennett, E. (1997). Mother-child relationships, teacher-child relationships, and school outcomes in preschool and kindergarten. Early Childhood Research Quarterly, 12, 263-280.

Pianta, R. C., Steinberg, M. S., \& Rollins, K. B. (1995). The first two years of school: Teacher-child relationships and deflections in children's classroom and adjustment. Development and Psychopathology, 7, 295-312.

Pianta, R. C., \& Stuhlman, M. W. (2004). Teacher-child relationships and children's success in the first years of school. School Psychology Review, 33, 444-458.

Rudasill, K. M., Rimm-Kaufman, S. E., Justice, L. M., \& Pence, K. (2006). Temperament and language skills as predictors of teacher-child relationship quality in preschool. Early Education and Development, 17, 271-291.

Seccombe, K. (2000). Families of poverty in the 1990s: Trends, causes, consequences, and lessons learned. Journal of Marriage and Family, 62, 1094-1113.

Sheldon, S. B. (2002). Parents' social networks and beliefs as predictors of parent involvement. The Elementary School Journal, 102, 301-316.

Simpkins, S. D., Weiss, H. B., McCartney, K., Kreider, H. M., \& Dearing, E. (2006). Motherchild relationship as a moderator of the relation between family educational involvement and child achievement. Parenting: Science and Practice, 6, 49-57.

Stuhlman, M. W., \& Pianta, R. C. (2001). Teachers' narratives about their relationships with children: Associations with behavior in the classroom. School Psychology Review, 31, 148-163.

Watkins, T. J. (1997). Teacher communications, child achievement, and parent traits in parent involvement models. Journal of Educational Research, 91, 3-14.

Yeung, W. J., Linver, M. R., \& Brooks-Gunn, J. (2002). How money matters for young children's development: Parental investment and family processes. Child Development, 73, 1861-1879. 